\title{
THE MOVE FROM PAGE TO SCREEN: THE MULTIMODAL RESHAPING OF SCHOOL ENGLISH
}

\section{Carey Jewitt}

Published in Journal of Visual Communication (2002) 1(2): 171-196

\begin{abstract}
In the move from page to screen a range of representational modes (including image, movement, gesture, and voice) are available as meaning-making resources. In this paper I focus on the reshaping of the entity 'character' in the transformation of the novel $O f$ Mice and Men (Steinbeck, 1937), to CD-ROM (1996). Through detailed analysis I demonstrate that the shift from written page to multimodal screen entails a shift in the construction of the entity 'character'. I also suggest that students' interaction with the resources of the CD-ROM as a visual text demand that 'reading' and the process of learning within school English be thought of as more than a linguistic accomplishment.
\end{abstract}

Key words: Multimodality, Learning, CD-ROM, School English, Character. 


\section{INTRODUCTION}

\section{Multimodality and learning}

Research on computer mediated learning has tended to focus on people's practices with and around the computer rather than the representational resources of computers. The majority of this research in this area has focused almost exclusively on talk. There are some notable exceptions to this. For example, research on the structures of software design which support discussion in primary school classrooms (Wegerif, 1997), the impact of the narrative structure of CD-ROMs on learning (Laurillard, 1998) and the ideology of educational CD-ROMs (Zammit, and Callow, 2000). This focus on language reflects theories which view learning as a primarily linguistic process. (From this stance there is no need to look beyond language.) This paper is concerned with the representational resources of screen and people's interaction with these in the context of school English, and challenges the assumption that learning happens primarily via language.

In most learning contexts communication takes place through the complex interplay of a range of modes. These may include writing, visual communication (e.g. diagrams, pictures, video), gesture, and aural communication (e.g. speech, sound). In other words, communication and learning are multimodal (Kress et. al., 2001; Lemke, 2000). Computer-based texts, such as CD-ROM and Hypertext, are generally (although not always) highly multimodal. Although the continued role of writing in these multimodal texts is not in question, they do raise important decisions regarding the choice of the display mode (image, word, sound, etc.) (Lanham, 2001).

One outcome for research into learning with such multimodal resources is the need for methods and theories that attend to a range of modes of communication beyond language. Recently, social semiotic approaches have been elaborated to take account of modes and systems of making meaning other than language. This includes work on music/sound (van Leeuwen, 1999), action (Martinec, 1997), and visual communication (O'Toole,1994; Kress and van Leeuwen, 1996). In short, communication is the social production of systems of signs and meanings as a 'multimodal' phenomenon. This paper builds on this work by analysing how multimodal resources, especially visual resources, are used to realise the entity 'character' in the context of a CD-ROM.

\section{The notion of 'character' in school English}

This paper draws on video and observational data from a series of five English lessons with a Year 10 class (students aged $14-15$ years) at an Inner-London Secondary School. These lessons focus on the study of Steinbeck's novel, Of Mice and Men, a set text in the English GCSE curriculum. The entity Character is central to school English. It is highlighted by the emphasis on character throughout the history of English; its prominence in the National Curriculum; and at a more local level the course work set by the teacher. 
As an academic subject English began in the working men's colleges of Britain with an emphasis on the transmission of moral values to the working class. Morality was an essential part of the ideological project of English. This was advanced by the work of among others F.H. Bradley and the F.R.Leavis (Eagleton, 1983). For the leavisites literature and society were intimately bound together. In this theory of literature the very stuff of reality was thought to be reflected in great works of literature. Literature which enabled the communication of strong moral values through dramatic enactment was encouraged. Such literature it was thought offered the potential for students to discover a spiritual home, and ultimately to discover the self through reading it "...[to] know how they came to be as they, very idiosyncratically, are." (Kermode, 1979:p. 15). This notion of literary character is realised in Steinbeck's writing. Throughout the twentieth century the traditional notion of literary character as a means for knowing oneself has underpinned an oblique form of moral education in British schools. The residue of this legacy persists in the English curriculum inclusion and exclusion of authors and texts such as Steinbeck's Of Mice and Men.

The study of set texts is a central element of school English. GCSE English course-work and examination includes the demand for responding to a set text by recommended authors. The English National Curriculum programme and assessment schema highlight 'character' as a core entity. Understanding character is explicitly specified as central to a critical and creative response to a range of texts. Students are expected to demonstrate how character' is constructed through an author's choice and style of language. Students are also assessed on their ability to make comparisons between the characters in a text and their role in the narrative, and to demonstrate the motivation and behaviour of a character through the analysis of a text (DFEE, 1999).

The teacher focused on the entity character in the course work she set the class. The course work set was to write 'a day in the life' of a character from Of Mice and Men. The students had to select a character of their choice for this work.

The focus on character in official versions of English and classroom versions of English suggests that it is important to understand how character is realised in the CD-ROM. In the following section of this paper I give an overview of the CD-ROM, and then describe the multimodal reshaping of the characters firstly in the 'Novel as CD-ROM' and secondly in the Dossier section of the CD-ROM. Through this analysis I show that in addition to the reshaping of characters within the novel, the traditional notion of character described above is also reshaped (gets a new form) in the move from page to screen. I return to the question of what this reshaped character might mean for learning later in the paper.

\section{Overview of the CD-ROM}

The CD-ROM Of Mice and Men is organised into five parts: Novel as CD-ROM, Biography, Map, Diary, and Dossier. Each of these parts of the CD-ROM are selected 
from the opening screen. These five parts of the CD-ROM draw on a range of modal resources in order to focus on discreet aspects of the study of a text.

\section{Figure1: map of CD-ROM}

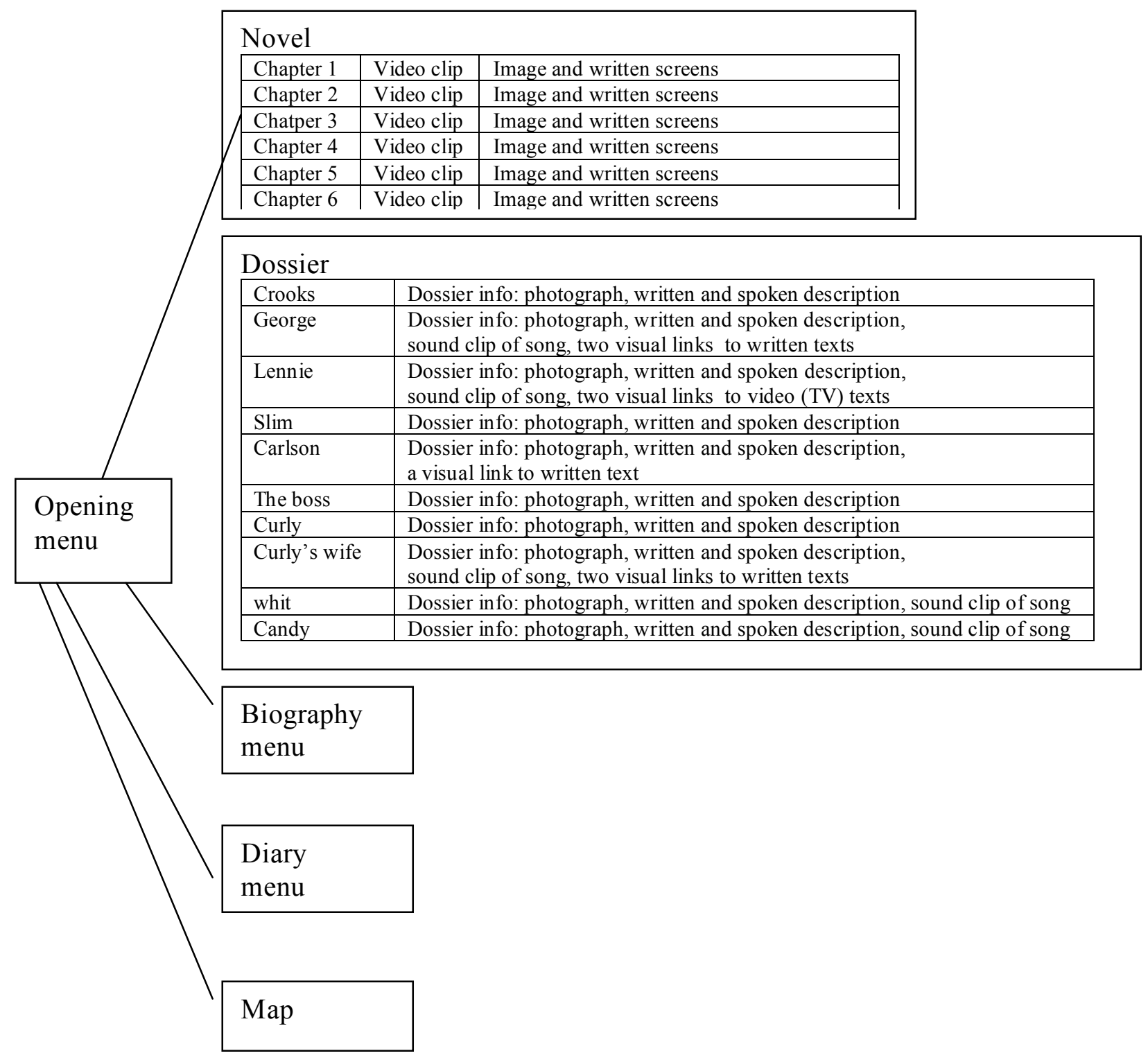


The 'novel as CD-ROM' offers two viewing options titled, 'Text' and 'Visual'. The Text option, as the title suggests, is a written text. The use of Times font on a plain white background in the Text option emphasises the visual plainness of the text. In contrast, the 'Visual' option uses a range of aural and visual modes. Each chapter includes a video clip, bringing the modes of speech, voice, music, movement and gesture into play. It also includes a series of still image and written text screens. Each screen is filled with a still image, and a block of writing. The Visual option also includes visual hyperlinks (in the form of words circled in red, italicised, or underlined) which link to other sections of the CD-ROM (such as, the Map part of the CD-ROM, or commentary on the text). The Visual option also includes a character guide, Bindy, in the form of video clips of an actor, which offers a spoken commentary at various points (the guide is not discussed in this paper).

Figure 2: Map of Chapter 1

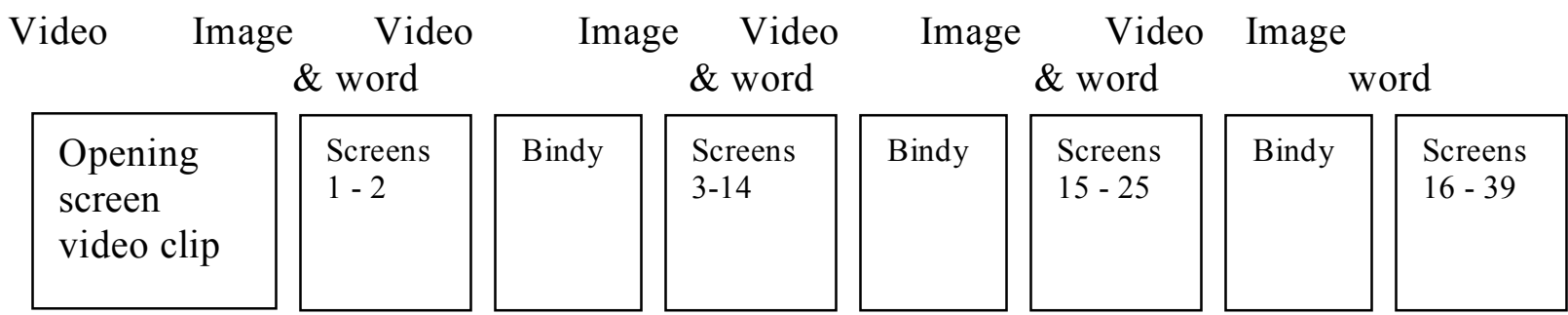

This paper focuses on the Visual option of the 'Novel as CD-ROM' for two reasons; first, it is the default option on the CD-ROM, and, second, it is the option used by the students in the lessons I observed.

\section{THE MOVE FROM PAGE TO SCREEN: THE 'NOVEL AS CD-ROM'}

In exploring the modal realisation of character on screen I treat the 'novel as CD-ROM' as a transformation of the printed novel. The CD-ROM is the product of designer's modal re-shaping of the character from the mode of writing to the multiple modes of the screen.

Many books, including Of Mice and Men, have been transformed from novel into film. The move from the 'concept of the mental image' to the 'percept of the visual image' is the root difference in this transformation (Bluestone, 1973). The medium of book and film have different properties including different: origins, resources for making meaning, relations to times and space, conventions, and audiences. I suggest that the resources of transformation in the move from the novel Of Mice and Men to the CD-ROM differs from the move from book to film. The CD-ROM has different properties to film which allow it to both transform and maintain the presence of the original text, and it is explicitly framed as a pedagogic text. 
The transformation of the novel, Of Mice and Men, from printed page to electronic screen via the CD-ROM draws on the modal resources of image, sound, and action in three ways. First, the transformation of writing into multimodal video clips using voice, music, movement, body-posture, gesture, clothes, composition, and editing. Second, the addition of still image throughout the 'novel as CD-ROM'. Third, the addition of the video character guide 'Bindy' to the 'novel as CD-ROM'. I suggest that these modal resources are a part of the shaping of the students' 'reading' of character (Graddol and BoydBarrett, 1994).

In providing a textual-reading of the CD-ROM I am not suggesting that there is one reading of it. This textual-reading is an attempt to describe the meaning potentials made available via such multimodal transformations. My analytical focus is at two levels. First, at the level of the resources on screen; and second at the level of a reader's interaction with these resources.

I focus on Chapter One of the 'novel as CD-ROM' to describe these modal changes in detail. This chapter is typical in the use of mode, structure (shown in figure 2), and the relationship of the 'novel as CD-ROM' to the original novel.

Chapter One introduces the characters Lennie and George and narrates their journey to the Speckle Sugar ranch.

\section{Writing to multimodal video text}

The CD-ROM version of the chapter opens with a short (50 second) video clip. It shows the characters George and Lennie sitting by a campfire, talking. This scene in the CD ROM draws on pages $15-16$ of the printed novel (the chapter in the book is 18 pages in total). The 'novel as CD-ROM' effectively 'opens' near the conclusion of the chapter. The move from writing to multimodal text is described in the transcript below (figure 3 )

Figure 3 (separtate file)

\section{The visual representation of action}

The transformation of the scene of George and Lennie around the campfire from page to screen opens the possibility for representation through actional modes. The choice of video clip as opposed to an audio clip can be seen as motivated by modal considerations. Actional modes, by which I mean movement, posture, gesture, and gaze, offer different resources for meaning-making than sound. Movement as a mode, offers different possibilities than sound for realising rhythm and pace (fast/slow, smooth/jerking), it has spatial dimensions (close/distant), and directionality (up/down, left/right, in/out). Just as in sound there is the potential for silence, there is also the possibility of stillness in the 'lack of movement'.

Actional modes are used differently in the 'novel as CD-ROM' to construct the characters George and Lennie. The character George maintains the same body posture and position throughout the video clip (figure 1-image (a)). He is represented sat by the 
fire resting against a rock with his legs stretched out in front of him, and leaning slightly toward Lennie. He looks steadily at Lennie and maintains the same direction and focus of gaze throughout. On one occasion he makes a soft rolling gesture with his hand. In contrast, the character Lennie is re-presented as sitting leaning against a rock with his knees brought up under his body. As the character Lennie starts to talk, he lunges forward, shifting the weight of his body forward, and leans across the fire and prods George on the shoulder (figure 1-image (b)). As he talks he moves his hands in a series of jerking gestures, and shifts his gaze from George to the surrounding woods (figure 1 image (c- d)).

This representation of the two characters' body posture, movement, gesture, and gaze serves to polarise them. The character George is represented as still, and relaxed (his body stretched out) an actional quality associated with calmness, and stability. The movement (springing, lunging), gaze, and 'prodding' gestures of the character Lennie represent him as unsettled, volatile, and unaware of danger (leaning across the fire). This transformation of the characters serves to reinforce the rational adult character of George, and the emotional child-like character of Lennie - who literally 'can't sit still'. This construction of the characters through actional modes shapes the viewer's relationship to the characters and understanding of their relationship.

\section{Distance of shot}

In everyday interaction the culturally established norms of social relations determine the distance we keep from one another to suggest different degrees of intimacy or formality. In the first shot the characters Lennie and George are represented from some distance, the long shot is a conventional shot for setting the scene. The second and third shots are closer, medium-shots, showing George and Lennie from the waist up (figure 1 - image (c) ). The increased closeness of these shots realises the characters' relationship, and perhaps the potential claustrophobia of George as Lennie gestures towards him (and the viewer).

\section{Point of view}

The camera encodes a viewing position, both in terms of distance, and in angle of representation. ${ }^{\mathrm{i}}$ That is, the viewer is 'placed' in a particular viewing position to the things represented. I am not suggesting that the viewer is bound to accept the viewing position encoded by the maker of an image. Viewers bring different ways of seeing to an image, and their meanings are the result of their negotiation, or even rejection, in the process of interpreting/engaging with an image at different historical-social moments (Rose, 2001). Nonetheless, viewing positions are encoded in an image and this is the resource offered as the basis for the negotiation of meaning. In the video clip, the point of view of the first shot shifts from a frontal angle (objective) to a slightly oblique angle in the second shot - an over-the-shoulder shot. (This is the standard way of representing a static dialogue scene in film.) This shift in angle 'places' the viewer close to the left of George. The visual focus is on Lennie as he talks and gestures. This contrast of angles (combined with the move in distance) serves to emphasise and objectify the action of Lennie from a viewing point close to the experience of George. In the third shot (figure 1

- image (d)) the viewing position is reversed: the camera (viewer) is positioned to the 
back-right of Lennie and the visual focus is on George as Lennie talks. The viewer is now looking at 'the visual experience of Lennie'; the calm smiling face of George who remains still and attentive. This use of angle and distance, although a standard filmic device, is to visually construct viewer empathy with the character George's 'experience' and the objectification of the character of Lennie. It also serves to further polarise the characters visually.

\section{Clothes}

Both in the book and in the CD-ROM clothes are used to construct the relationship between the characters in different ways. In the book the characters George and Lennie are represented as, both dressed in denim trousers and denim coats with brass buttons. It is the characters' physical features, their height and size, which distinguish them. In the CD-ROM, the characters George and Lennie are re-presented through their clothes (in addition to their height and build) to be different. In the CD-ROM the character Lennie is dressed in a flat cap and loose fitting dungarees cut from a pale light-weight denim. The character George is dressed in a dark brimmed hat, a well fitting dark brown jacket and jeans, and a check shirt. Clothes are used as social marker of visual difference. Lennie is dressed in clothes which are traditionally worn by children (and in the era of the book, the working class). George is dressed in clothes generally worn by adults. That is their clothes are associated with the power of social position, child, and adult. In this way, clothes are a visual sign which suggest Lennie's dependence on George.

The shared social position of the characters Lennie and George which is significant in the novel is transformed in the visual mode of video on the CD-ROM. The use of clothes to visually position George and Lennie's relationship as an adult- child relationship presents a filter through which George's anger and attempts to control Lennie in Chapter One can be read as acceptable within a contemporary context. The imbalance between the two characters is visually highlighted. The nature of the friendship between George and Lennie is visually placed in the context of 'family' - which reduces the potential for their friendship to be read by a contemporary audience as a gay relationship.

\section{Design}

Composition and editing are means for the visual design (organisation) of a range of modes in the video clips. They provide a range of resources for the arrangement of elements in a visual space, in this instance the visual space of the screen. In the video clip, the two characters could be represented on screen at the same time, or the camera could move between each character (depending on who is talking). One character could be placed in the foreground or background, on the left or right of screen, or in the centre. Designers and viewers interact (read and make sense of) with these resources of arrangement to construct meanings. The way in which elements are placed in relation to each other on screen produces relations between them which express different potentials for meaning. Camera movement between the two characters, for example, may be used to suggest dialogue (this may be unspoken, e.g. in the form of a gaze). The compositional framing of two characters on screen may visually realise intimacy or unity. 
In the first shot (figure 1 - image (a)) the screen-space can be 'divided' into three vertical 'zones'. Each of these 'zones' is occupied by a different element. The left is occupied by Lennie, the middle by the fire, and the right by George. Looking at the screen as a triptych compositional arrangement of space in this way suggests that the relationship between Lennie and George is mediated by 'fire' - a symbol of warmth. During this shot, the character George consistently occupies 'his own space'. In contrast, the character Lennie moves across the fire to gesture and touch George in a kind of lunging movement. The character Lennie's movement from the 'zone' he occupies into the 'zone' occupied by George disrupts the equilibrium of the visual arrangement of spatial zones. It is this movement which heralds the first edit of the sequence. The edit therefore serves to emphasise Lennie's disruption of George's space it further with a shift in viewer distance and angle. In the next two shots the characters are both represented, but compositionally it is Lennie who dominates the space of the screen and who is visually foregrounded (figure 1 - image (c) and (d)). Lennie is represented as 'breaking' the spatial framing/boundaries of the screen. The character Lennie is represented as disruptive through his movement in this compositional space. The stillness of George and his boundaried spatial framing adds to the multimodal construction of his character as 'stable'.

\section{Dialogue to speech}

Although this paper is primarily focused on the visual, other modal resources, such as speech and voice contribute to the multimodal transformation of character. The voice of the character George is represented as slow, and clear - each word is distinct and boundaried - and he speaks in a level tone. His voice is relaxed, smooth, neither soft nor loud, full, and unwavering. In contrast, the voice of the character Lennie is quick, and stuttering. As he speaks his voice is breathless, his words are shortened, the words run together and become mixed-up. He talks loudly, and the words 'shake' as they stumble out of his mouth. This representation of the characters' through voice is the result of choices from a range of aural possibilities, choices which carry meaning. The slow rhythm, normative level, and evenness of George's voice combine to form a sign of calmness and stability. The fast and faltering quality of Lennie's voice signal the value of instability and lack of control: the exaggerated stutter serves to remove any sense of clarity. This use of voice emphasises the contrast between the two characters, and marks Lennie's lack of control and potentially dangerous nature from the start. This provides a less sympathetic view of Lennie and places the relationship of Lennie and George in the context of control and power rather than friendship.

\section{Written text to visual text}

As the video clip described above ends, the screen fades to black, and a new screen appears. This screen shows a line drawing of a country road with an accompanying white block containing writing (occupying $10 \%$ of the screen). Chapter One has 39 screens each of which consists of a block of writing 'over' a drawing. The introduction of drawings to the text brings forth a range of resources for the realisation of the entity character (including frame, distance, angle, composition) which are discussed below. 


\section{Represented elements}

The characters Lennie and George appear in screen three. The images of the characters are narrative representations, that is, they present them as actors in a series of unfolding

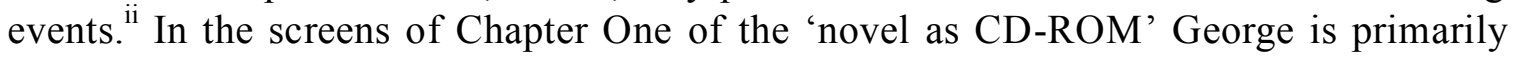
represented as engaged in an activity with a goal (transactional action). In contrast, Lennie is represented as engaged in non-transitive actions: he looks out of the screen with no visible goal, and we are left to imagine what, if anything, he is looking at in nearly a quarter of screens (8/39). The contrast between these visual representations of the characters signals George as active and Lennie as passive.

\section{Framing}

The framing of an image indicates the discontinuity or continuity between elements, and in what it is that separates or links the elements. ${ }^{\text {iii }}$ The framing of the images in Chapter One of the 'novel as CD-ROM' is a visual sign of the closeness and status of the relationship between George and Lennie. The two characters are represented together in nearly two-thirds of the screens (23/36), and often represented touching one another. Frame as a meaning-making resource is used to represented George and Lennie's togetherness, its disintegration, and its reinstation. George and Lennie are represented as close together (in the first 11 screens). George is then represented alone (two screens). There is a short moment of being together again (two screens), and Lennie is alone again (two screens); this is followed by a moment of being together (two screens), and then Lennie is again alone (one screen). This is followed by a series of screens in which they are shown together but are framed as apart (six screens). Finally the distance between them is removed and they are framed together in a sequence of close-up images (7 screens). As a resource, frame is used here to display a visual rhythm of the characters' interaction. In this way frame realises both the intense character of their friendship, and its volatile nature.

The 'disconnected nature' of Lennie's character is also suggested by framing. The character is represented as being alone in nearly a quarter of the screens (9/39). This draws on contemporary visual representations of the lone male as stalker, rather than the empathetic loneliness of the original novel.

\section{Social distance}

As discussed earlier social distance can be visually encoded to suggest the designers' desired relationship between viewer and the represented participants. In the images of Chapter One mid and long shots are used to represent George and Lennie walking or Lennie standing looking out of screen. Close-up images are employed in four instances in Chapter One: Lennie drinking from the river; Lennie looking frightened in the dark; George holding his head in his hands; George and Lennie talking. Overall, George is more frequently shown in close up than Lennie. Overall, Lennie is most frequently shown in mid-long to long shot. Throughout the chapter close up images of the characters are used to visually emphasise the intense emotions which are key to the characters and their relationship: Lennie's lack of control and fear and potential physical power; George's frustration and guilt. 


\section{Attitude}

The horizontal angle between the represented participants and the viewer encoded in the images of Chapter One indicates the suggested level of involvement between them. Through the use of angle and distance in the still images, the viewer is placed at a greater distance to the character Lennie. The viewer is positioned to observe rather than engage with his actions and emotions. In some screens angle and distance are used to visually represent Lennie as a 'potential danger'.

\section{Compositional relationship between image and writing}

The amount of screen space occupied by image and writing on each of the screens varies through out the chapter. The ratio of image to writing varies the between $5: 1$ and $3: 2$. Image dominates the screen-space in the majority of the screens: over half of the screenspace is occupied by image in over three-quarters of the screens. Writing on the screens is displayed in a white rectangular block, the edges of which are roughly drawn. It has been argued that the visual elements of the screen in CD-ROM versions of books distract students and that visual and written elements should be separated (Graham, 1994). In contrast, I suggest that the spatial relationship between image and writing on each of the screens of the visual version of the 'novel as CD-ROM' is itself a visual meaning making resource. In other words, writing serves as a visual element, a block of 'space' which makes textual meaning beyond it's content. The move from page to screen can be understood as a shift from the organisational rules of the page to the organisational rules of the visual. ${ }^{\text {iv }}$ When writing is present in the multimodal environment of new technologies it its visuality is foregrounded, and the use of the visual is expanding. Indeed, written elements on screen are now considered by some to be merely what cannot be done in images (Boulter, 1999). New technologies offer the potential to 'recast modes' in ways which blur the boundaries between the visual and the written. This shift to the visual is apparent in the 'novel as CD-ROM'.

The blocks of writing are positioned on the screen in different places: the left or right side, along the bottom or top length of the screen, or in the top or bottom corner. Depending both on the size and position of the block of writing different parts of the image layered 'beneath it' are revealed or concealed. In this way a block of writing (and its movement across screens) emphasises different aspects of the image on the screen. At times a block of writing changes the screen image fundamentally (e.g. by concealing either George or Lennie). This interaction between the visual and the written element on screen in the 'novel as CD-ROM' emphasises the actor, and visually marks the intensity of a moment - through persistence on screen. At times the image cuts across the Lexis and grammar of the written element to create a visual mood and rhythm. For example, the image of George and Lennie shown in figure 4 runs across three screens. 
Figure 4: The relation of image and writing over three screens
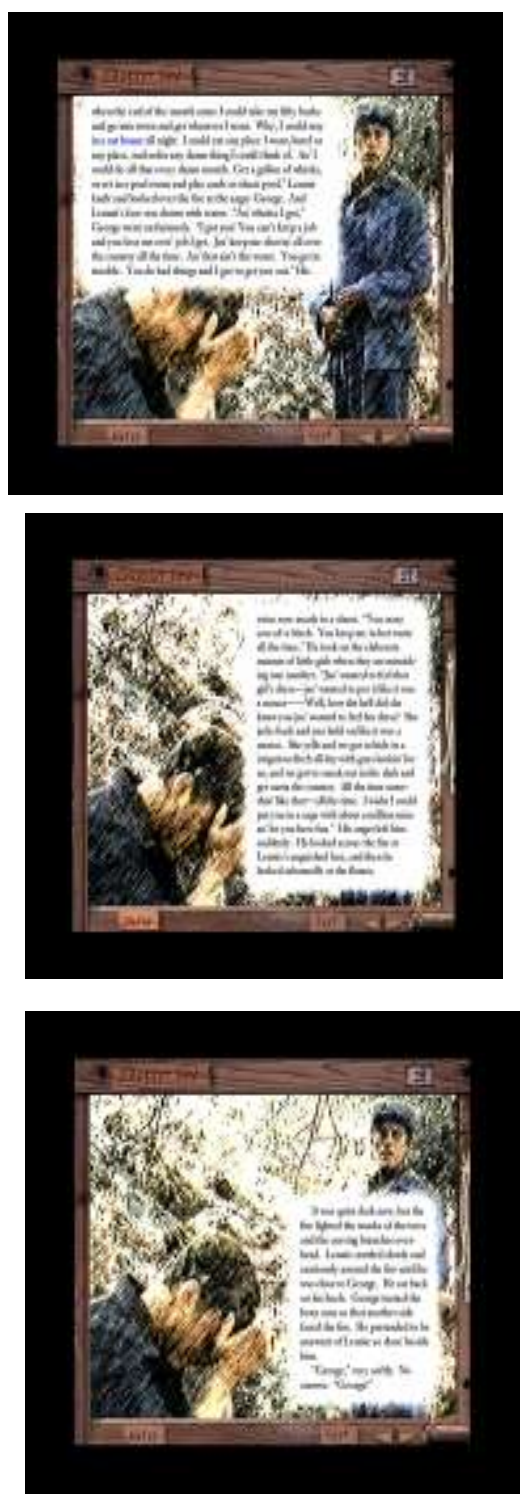

In the first screen, the block of writing sits above George's head as he talks to Lennie about what he could do if he left him. In the second screen Lennie is visually obliterated by George's angry talk of leaving visually forgrounding George. In the third screen as George's anger subsides the block of writing is placed on screen so that both George and Lennie are visible. The writing focuses on the thoughts, worries, and dreams of George. The image and writing 'attend to' separate aspects of the narrative. Mode is used to emphasise George's isolation and lack of power. At times image and writing appear to 
'belong' to the two characters differently: Lennie is more frequently represented as expressing himself visually, and George more often through writing.

\section{Student interaction with the 'novel as CD-ROM'}

While the focus of this paper is on the resources made available via the CD-ROM I want to comment briefly on how some students interacted with these resources and their 'reading' of the 'novel as CD-ROM' as a visual text. In the novel the entity character is realised through the written description of movement, gesture, appearance, and speech. The 'novel as CD-ROM' represents character multimodally. A character's voice is heard, bringing voice into play as a mode and with it a set of semiotic resources for meaning making - voice quality, rhythm, tenor, pitch, and so on (van Leeuwen, 1999). A range of actional modes are also made available visually via video, including facial expression, posture, gesture, movement, and clothes. These visual and aural resources shape the representation of character. These potentials are selected, and 'designed' (configured and arranged on screen) into texts which shape (re-present) the entity 'character' in specific ways. Multimodal texts such as these not only 'powerfully enrich the resources of a book' (Goodwyn, 2000), and provide new resources for students to engage with in the their construction of character.

It has been suggested that CD-ROMs enable learners to determine their own route through materials (Andrews, 2000), and that reading from screen offers a less alienating experience of a text (O'Donoghue, 2000). I suggest that interaction with the 'novel as CD-ROM' in this instance extends the notion of reading.

The 'novel as CD-ROM' 'read' as video

Here I give a brief account of two students engagement with the 'novel as CD-ROM'. Student 1 and Student 2 'open' it, and quickly close the first video clip (as the first video clip opens automatically when the 'novel as CD-ROM' is selected they have seen the scene many times). Student 2 has memorised the rough location of the video clips via the 'page numbers' displayed in the top right corner of the screen. He and Student 1 use this information to find the first two video clips that they watch. Student 2 types in the page number on the computer keyboard and instructs Student 1 to move backwards or forwards using the icons on screen until the video clip is found and opened. He has memorised the elements in sequence (what goes before, and what comes after) to locate the video clips: he has internalised the structure of the visual narrative. Having located the video clips the two students sit back, hands off the mouse and key board, and watch the video. Later they realise that the video clips are always at the start of a chapter and they switch to using the Chapter Menu Bar to find them.

The use of the Chapter Menu Bar as a navigational tool enabled the two students to move almost seamlessly through the 'novel as CD-ROM' as a series of video clips. The students by-pass the novel as a written text (i.e. they do not engage with it) and instead engage with it as a (multimodal) video text. 
The 'novel as CD-ROM' 'read' as comic

Two students, Student 3 and Student 4, first watch the video clip described earlier. As the video clip closes the screen of the first page in the 'novel as CD-ROM' automatically opened. Student 4 instructs Student 3 to "keep going along", and Student 3 clicks the forward icon with the mouse. As the character guide Bindy appears she clicks to move on, but cannot. The two students watch the screen, Student 3 holds the mouse. As Bindy closes, Student 3 clicks the forward icon every two or three seconds moving through the next 12 screens in this way. Both students lean forward to the screen and look directly and intently at it. The next clip of Bindy opens, the students watch him, and then Student 3 clicks the forward icon to move through the next nine screens of the "novel as CD ROM'. As the next Bindy clip opens, Student 3 appears to try and close it, and failing that, to try and leave the 'novel as CD-ROM', Student 4 instructs her to stay in the 'novel as CD-ROM' area and to "keep going". Student 3 clicks on the forward icon every 2 seconds and moves through the next 14 screens. The second video clip, in which Lennie and George meet the boss of the ranch opens. Student 3 takes her hand off the mouse and both students lean back in their seats and watch the video clip. The students' 'flicking' movement through the still images of the chapter 'animates' the text like a cartoon. The two students then watch the film clips. In this way the students genre of interaction with the text served to reshape the entity character by shifting the high literacy aesthetic of 'Novel' to the low popular textual genre of comic and film.

\section{The multimodal reshaping of character in the Dossier section of the CD-ROM}

The Dossier part of the CD-ROM is an explicit construction of character as an entity and draws on a range of modes, in particular the visual. The Dossier provides a 'file' on the characters of the novel. The range of modes in each file varies, as does the number of links to other screens, and the number of visual objects (photograph, visual objects, written text). These factors (mode, link, and objects) can be read as a visual indicator of the importance of a character.

The widest range of modes (including, voice, image, writing, movement and speech) are used to display the information in the dossiers of these characters - Curly's wife, Lennie, and George. These dossiers include twice as many visual objects on screen, and three times as many visual links as the others. Through these multimodal resources the three characters, George, Curly's Wife, and Lennie, are represented as equally important. The character Curly's wife is modally repositioned from a marginal to a central character. In addition, the dossier reshapes her character by visualising her vulnerability (in a series of photographs) and the telling of her perspective on life via the mode of voice and song.

The visual sharing of objects and links across character files enables students to pursue textual and thematic issues (Goodwyn, 2000). In this CD-ROM shared objects appear to be a visual indication of a relationship between characters. Meaning is constructed from the juxtaposition of different texts, and events which unfold 'through reading across and among various media' (Zancanella et al., 2000: 99). Several character files contain shared visual objects: Curly and Curly's wife; George and Lennie; and George and Curly's wife. Through the use of a shared image of a hand addressed envelope in the files of George and Curly's wife the Dossier visually introduces the suggestion of a 
relationship between them. The addressed envelope is suggestive of a romantic, secretive relationship. The visual link between the two characters is also suggested through the use of audio clips in the Dossier. George sings mournfully alongside a clinky music hall style piano:

"... a guy sick of the life he has known, he hopes some day to meet a girl, a girl who will be his own, a girl, a girl...."

Almost as if in response Curly's wife sings:

“...I got a man who ain't never home, Got no one to be with me, I got no women folk livin' near by, I'm too much a lone, Just someone to talk to, Nothing more, nothing less, Any little words at all, Take away the loneliness..."

Through the visual and aural re-shaping of character the potential for a relationship between George and Curly's wife is presented in the CD-ROM. This introduces a heterosexual romantic strand into the narrative which serves to realise the vulnerable femininity of Curly's Wife and the heterosexuality of the character George.

The character, Crooks, is also visually repositioned via the Dossier. A photograph in the character dossier shows the character Crooks cleanly dressed, standing in a tidy room, looking out at the viewer with an intense gaze. The images also shows his possessions neatly organised, including a collection of books and a light - visual props to mark his intelligence. The visual presentation of Crooks within the same frame as the other characters in the Dossier serves to equalise the characters. The original description of Crooks from the novel is read by a male narrator as the file is opened. His voice is deep, full, and 'church-like', he reads the description of Crooks in a slow voice indicative of gravity and respect. Through this use of image and voice, the character Crooks is removed from the racist animalistic textual context of 'nigger' and 'stable-buck' in the original novel.

The modal transformation from page to screen does not demand these shifts in the centrality or representation of characters, rather it makes it possible to reshape the characters and their relations, at the same time as maintaining the original novel as a text. The reshaping of the novel occurs in the designer's use of visual and aural modes, while the mode of writing is used to maintain (reproduce) the text of the original novel. The multimodal reshaping of the characters Curly's wife and Crooks repositions the novel for a contemporary audience. The potential to read the novel as sexist and racist (a view expressed by some of the students on reading the novel) is visually 'overlaid'. 


\section{Students' multimodal 'readings' of the Dossier}

Having read the Novel, Of Mice and Men, but prior to using the CD-ROM, the majority of students chose George or Lennie as the focus for their course work ' a day in the life of'. After using the CD-ROM the students chose a broader range of characters for their course work including, the Boss, Crooks, Slim, Curly, Curly's wife, George and Lennie.

When exploring the CD-ROM Dossier, one student Student 5 repeatedly selected and viewed the file of Crooks. Student 5 changed his choice of character for the course work to Crooks. When asked why by the teacher he gave the following reason:

Student 5: I changed my character to Crooks, cos he's like the only Black man there and he's very lonely.

Teacher: you knew Crooks was the only Black man in the novel when we read it, so what made you change your mind after looking at Crooks on the CD-ROM then?

Student 5: the dossier give me more information about him, because the book don't really talk about him, it, as being a shy man, and um the description of his room as a ...Dung Heap.

The Dossier files represent each character 'decontextualised' from the original novel. While on the one hand it is problematic to decontextualise character from narrative, on the other hand it appears to provide a new opportunity for students to engage with the novel and with the characters. The visual decontextualising of the character in the Dossier, and the visual re-shaping of the character Crooks in the video of the "novel as CD-ROM' re-present the character Crooks as a person removed the character from the racist animal-like context of 'nigger' and 'stable Buck'. The re-shaping of this character appears to have provided Student 5, a young Black man, with a new potential to identify with the character. That is, the resources of the Dossier served to provide a visual multimodal filter with which to engage with the characters within the context of the novel.

Several students' interaction with the Dossier section of the CD-ROM was mediated by the combination of image, music and song. These students selected the character files with visual links to songs. Just as Student 2 and Student 1 'watched' the 'novel as film', and Student 4 and Student 3 'read' the 'novel as comic', these students engaged with the 'novel as musical'. Song and music was a central feature of several students' engagement with the character Curly's wife. During one 50 minute lesson, for example, two students returned to Curly's Wife's song on three occasions, learnt some of the words, and quietly sang along to the chorus.

Student 4, and another student, Student 6, decided after using the CD-ROM to focus on the character Curly's wife character in their course work:

Student 6: I'm doing Curly's wife

Teacher: And that's a change isn't it? You didn't do Curly's wife before?

Student 6: No I did Lennie before.

Teacher: So why have you changed?

Student 6: I didn't know that she sang. 
T: You like the song. And what was it about the song? Because I think you and [Student 4], because both you and [Student 4] have chosen to do Curly's wife, it's a change for both of you. And I think for both of you the song was very significant wasn't it?

[student 5 and student 4 nod heads]

T: So [Student 4], what is it about the song?

Student 4: I liked listening to it, one reason I liked it is cos when she's singin' its about how she feels, and, and that's what I think.

The song appeared to play a central role in these two students' identification with the character. The song literally 'gave voice to' the character Curly's Wife. The character's singing presented them with an insight into her emotional life via her voice. In the process the character was transformed from a hardened vamp into a victim of a sexist society. Through her voice, the music, and the words of the song the character Curly's Wife in the 'novel as CD-ROM' was drawn into the inclusive theme of loneliness. The 'knowledge' that she sang (rather than the song itself) appeared to be key in the reshaping of the character for Student 6. Perhaps for this student singing is a metaphor for emotion. As was the case for Student 5, the multimodal re-shaping of the character provided these students with a different potential for engagement with the character Curly's Wife.

\section{MULTIMODALITY, NEW MEDIA AND LEARNING}

The resources of page and screen offered students and teacher different possibilities for engaging with specific characters and the construction of character as an entity, and brought forth quite different practices of interaction.

\section{Textual evidence}

The Dossier part of the CD-ROM enabled the students to engage with the entity character independent of the novel itself. In doing so, the CD-ROM offered a model for studying the text for characterisation: the segments of the novel selected as 'textual evidence' explored characterisation as a symbolic device through visual objects and links. Further, the potential to explore the entity character dislocation from the narrative appeared to provide a potential for some students to identify with marginal or negatively portrayed characters. In addition, placing the characters within a shared format of display appeared to have an equalising effect on characters.

\section{Sociocultural context}

The structure of the CD-ROM provides a modal commentary on the work of studying character within a set text: the expectation that character be understood in its sociohistorical context, and the need (literally) to move beyond the immediate text. That is, the structure of the CD-ROM provides a reflexive tool for the study of character as an entity. The organisational structure of the CD-ROM Dossier and the 'novel as CD-ROM' visually models the need to move between studying character at the level of the novel as fiction, placing character (and the novel itself) in a historical context.

In the Dossier the screens which automatically open when a file is selected include a spoken and written description of the character, a photograph of the actor who played them in the 1992 film version of the novel, and in some files a collection of visual objects and hyperlinks. This 'default' screen is a multimodal engagement with the entity 
character within the 'fictional domain' of the novel. Selecting a visual object link on the screen leads to a domain of 'linguistic' commentary on character as an entity. These linked texts are intertextual references, either in the form of factual texts (such as letters from Steinbeck about a character, the actor who played a character, or an academic writing about the character) or spoken, sung, or written references to the construction of character within productions of the novel. This level can be seen as a 'factual domain' beyond the fictional novel. That is, fiction is constructed via the visual, while fact is constructed via 'language' written, spoken, or sung. In the case of the 'novel as CD ROM' visual hyperlinks (and the multimodal character guide 'Bindy') enabled students to move between the entity character in the novel as a text in the 'fictional domain', and the historical-social construction of character in the 'factual domain'.

This structure indicates that two different kinds of engagement with the entity character and the 'novel as CD-ROM' more generally are required of the student. The first, at the level of display, demands the students' imaginative engagement with character. The second, at the level of language (written, sung or spoken), demands engagement with the social-historical context of the novel and its subsequent 'life' as a text. The ideological expectation in school English that students should move beyond a text when they engage with it, is embedded in the multimodal orchestration of the CD-ROM, in particular, the relationship between visual, aural and written elements.

\section{Intertextuality}

While the 'novel as CD-ROM' does the 'imaginative work' of constructing the characters it also offers an intertextual construction of the entity character. In addition to the multiple layers of the 'novel as CD-ROM', the Dossier offers images, artefacts, and audio clips from film and stage productions of the novel. This provides a potentially more complex notion of character. Character is represented not as the product of one person's design/reading, rather it is represented as the multimodal outcome of interaction with many voices and modes over time. This represents the entity character as a dynamic entity which emerges from a social rather than an individual reading.

\section{Multimodality}

The multimodal resources of the CD-ROM demanded students engage with the entity character at the level of mode (visual appearance, action, voice) and at the level of narrative. The multimodal transformation of the characters via the resources of the CD ROM also repositioned the novel to account for the imagined concerns of a contemporary audience in an educational context.

The opening scene of the first video, for example, shows the intimacy of the two characters George and Lennie. In doing so the theme of relationships and friendship is visually foregrounded. The characters George and Lennie are polarised by the contrastive use of appearance, clothes, voice, gesture, composition and editing: any sense of sameness is removed by this multimodal reshaping. Further, through these visual resources the relationship between the two characters is constructed as an adult-child one. This reshaping of the characters presents a new set of motivations for character and narrative. 
Through the visual arrangement of image and writing on screen in the "novel as CD ROM' the entity character (through resources such as framing, and spatial relations) indicates the intensity of emotion, to suggest viewer identification with George, and to emphasise the agency/passivity of the characters in the novel.

The multimodal resources of the 'novel as CD-ROM' also serve to emphasise particular characters and moments of the story. First, characters were literally given appearance and voice. Second, they appeared in the repetition of moments in the three different forms video, still image, and writing. The pace and thematic emphasis of the structure of the 'novel as CD-ROM' is transformed by the placement (and repetition) of what are effectively concluding 'moments' at the start of each chapter via the video clips. These clips immediately foreground the entity character rather than other aspects of the narrative in a way which shifts the focus of reading the text from the social to the individual. Further, the use of visual links and objects in the Dossier part of the CD ROM also served to re-position, make central, the marginal character Curly's Wife.

\section{Practices of learners}

The work of the students was to interpret this multimodal representation of character. 'Reading' or perhaps more aptly 'watching' the 'novel as CD-ROM' introduced new resources and practices for constructing and understanding the entity character. The multimodal organisation of the 'novel as CD-ROM' offered students a range of modes with which to engage with it including, video, image, or image and writing. I suggest this enabled students to engage with character and narrative at different levels of reading. The video clips provide a multimodal construction of character and the realisation of the themes friendship and loneliness. These are atomised from the context of the novel and centred on affect and emotion. The screen images throughout the 'novel as CD-ROM' enabled a deeper exploration of character in the context of the sequential unfolding of the events, changing relationships, and locations. Finally, the written text realises character through the narrative descriptions of the novel. In the 'novel as CD-ROM' choice of mode is a choice of the level (detail) of engagement with the entity character.

These multimodal resources enabled students to 'navigate' the entity character modally in different ways via song, image, written description, or via the video clips. Several students for example engaged with the entity character entirely via song. This temporarily transformed the 'novel as CD-ROM' into a musical performance/sound track. Several students 'watched' the 'novel as CD-ROM' in the form of a film. Others 'read and animated' the images via their movement through the text momentarily overlaying the 'novel as CD-ROM' with the genre of comic. In short, the resources of screen enabled the students to bring different genres of engagement to their interaction.

\section{CONCLUSION}

Engaging with the book Of Mice and Men required the students and teacher to build on the frame of writing. They read to imagine the characters, their motivations, emotions, appearance, voice, and so on. The students identification with the characters and the moral dilemmas they encountered is foregrounded in this reading. The multimodal 
transformation of the novel Of Mice and Men to CD-ROM offers a specific reading of the novel. It reshapes the characters, their relations and motivations, and the narrative. It 'fills in' the descriptions of the characters: it 'does' much of the imaginative work demanded of the students as they read the book. The electronic reorganisation of original text into the CD-ROM is atomised, the narrative is disrupted, and the issues of morality brought about by the careful written webs of connections are ruptured and diffused.

The CD-ROM provides the students with different tools to things to think with in their engagement with character which reflect the demands of the curriculum. The CD-ROM reading of character is not a question of morality and identification, the reader will not come to know themselves, the reader will come to know the text for examination. The task for students is to understand character through their writing not through their lived morality. Character is not a matter of personal growth, but an analytic textual device. The merging of voices in the Dossier of the CD-ROM offers an explicit notion of character as an entity produced by many people over time rather than the stable authoritative voice of the author. Character is presented not as a stable moral emblem but a fluid entity which demands to be read in a social-historical context beyond the text. This suggests that the entity Character is not the product of an individual reading but the outcome of a collective social reading.

Amongst all the uncertainty of what it is to engage in a meaningful way with new media in school English it is clear that the expansion from novel to screen has implications for traditional notions of literacy and learning. The students' engagement with the CD-ROM described in this paper suggests that the genres and practices of reading such multimodal texts remain relatively open for the time being. 'Reading' or perhaps more aptly 'watching' the 'novel as CD-ROM' introduced new resources and practices for navigating, constructing and understanding the entity character. In this multimodal

environment it is clear that to persist in thinking of learning English primarily in terms of writing and speech is problematic. Doing so only serves to highlight 'the cultural chasm between adult and child, with the child clearly seated in a visual world' (Underwood, 1999:110).

\section{Acknowledgements}

I would like to thank the school, teacher, and students whose work in the classroom provided the material for this paper. I would also like to thank Gunther Kress for his helpful comments on this paper.

\section{References}

Andrews, R. (2000) 'Framing and design in ICT in English', in Goodwyn, A. (ed.)English in the digital age, London: Cassell: pp: 22-33.

Boulter, D. (1999) Writing space: the computer, hypertext, and the history of writing. Hillsdale, N.J.: Lawrence Earlbaum Assoc.

Bluestone, G. (1973) Novels into Film, USA: University of California Press. DFEE (1999) English: the national curriculum for England, London:HMSO.

Eagleton, T. (1983) Literary theory, Oxford: Blackwell. 
Goodwyn, A. (2000) 'An English teacher in the computer age', in Goodwyn, A. (ed.)English in the digital age, London: Cassell:pp:1-21.

Graddol, D. and Boyd-Barrett, O (1994) Media texts: authors and readers, Buckingham: The open University.

Kress, G. (2000) ' Multimodality', in Cope, B. and Kalantzis, M. (eds.) Multiliteracies, London: Routledge.

Graham, J. (1996) 'Trouble for Arthur's teacher: a close look at reading CD-ROMs', in Simons, M. (ed.)Where we've been articles from the English and Media Magazine, London: English and Media Centre: pp: 285-290.

Kermode, F. (1979) The genesis of secrecy: on the interpretation of narrative, USA: Harvard University Press.

Kress, G., Jewitt, C., Ogborn, J., and Tsatsarelis, C. (2001) Multimodal teaching and learning: the rhetorics of the science classroom, London: Continum.

Kress, G. and van Leeuwen, T. (1996) Reading images: the grammar of visual design, London: Routledge.

Lanham, R. (2001) 'What's next for text?', Education, Communication, and Information, 1(1),pp:15 -36.

Laurillard, D. (1998) Multimedia and the learner's experience of narrative, Computers and Education 31 pp: 229-242.

Lemke, J. (2000) 'Introduction: Language and other semiotic systems in education', Linguistics and Education, 10 (3), pp:307 - 334.

Martinec, R. (1997) Rhythm in multimodal texts, London Institute, unpublished paper.

O'Donoghue, M. (2000) 'To cope, to contribute, to control' in Goodwyn, A. (ed.)English in the digital age, London: Cassell.

Ogborn, J., Kress, G., Martins, I., and McGillicuddy, K. (1996) Explaining science in the classroom. London: Open University Press.

O'Toole, M (1994) The language of displayed art, Leicester: Leicester University Press.

Sefton-Green, J. and Parker, D. (2000) Edit play, London: BFI.

Steinbeck series: Of Mice and Men (1996), New York: Penguin Electronics.

Steinbeck, J. (1937) Of Mice and Men. London: Penguin.

Underwood, J. (1999) 'Review article: young children, videos, and computer games', Educational Research 41(1) pp: 110.

van Leeuwen, T. (1999): Speech, music, sound. London: Macmillan.

Wegerif, R. (1997) 'children's talk and computer software, in Wegerif, $R$. and Scrimshaw, $P$. (eds.) Computers and talk in the primary classroom, Clevedon,UK: Multilingual Matters, pp:99-112.

Zammit, K. and Callow, J. (2000) 'Ideology and technology: a visual and textual analysis of two popular CD-ROM programs' Linguistics and Education 10 (1): pp.89-105.

Zancanella, D., Hall, L., and Pene, P. (2000) 'Computer games as literature', in Goodwyn, A. (ed.)English in the digital age, London: Cassell: pp. 87-102.

\section{Biographical note}

Carey Jewitt is a researcher in the Culture, Communication, and Society Group at the Institute of Education, University of London. Her research focuses on multimodal teaching and learning across the curriculum, with a particular interest in the visual, and 
ICT. Her recent publications include, A Handbook of visual Analysis (2001), with T.van Leeuwen, and Multimodal Teaching and Learning: the Rhetorics of the Science Classroom (2001), with G.Kress, J.Ogborn, and C.Tsatsarelis.

\footnotetext{
i The horizontal angle between the represented participants and the viewer indicates the level of involvement between them. An oblique angle between the represented participants and the viewer indicates that the image maker did not align him or herself with the represented participants - they are represented as detached and outside of the viewers' world. A frontal angle indicates involvement between the viewer and the represented participant as it facilitates the viewer's identification with the represented participant(s).

ii The hallmark of a narrative visual representation is the presence of a vector (a vector determines the point of one position in space relative to another) which is usually diagonal and is formed by the depicted elements (bodies, limbs, tools) or a dynamic force in the image. The direction and source of vector(s) in an image are used to identify the kinds of action processes elements on screen are represented as engaging in. Action processes emanate from an actor and be either aimed at another participant - transactional actions, or not - non-transactional actions.

iii Framing indicates that elements of a composition can either be given separate identities, or represented as belonging together. In other words, framing 'connects' or 'disconnects' elements. Disconnection can be created in many ways, through frame-lines (which may be thick or thin: there are degrees of framing), through empty space between elements, but also through contrasts of colour or form, or any other visual feature, in short through any form of discontinuity, disconnection or contrast that can be visually signified. Connection can be achieved in exactly the opposite way, through similarities and rhymes of colour and form, through vectors that connect elements, and of course through the absence of frame-lines or empty space between elements.

iv That the computer-screen has not always been occupied by the visual, in the same way that you can write on a canvas, or paint on a clip-board, does not undermine the visual character of the site. 'Old' technologies always occupy new technologies (as witnessed by the running boards on cars, the key boards on computers). The question of whether or not these technologies are best suited to the spaces they occupy is something which can only resolved over time. I suggest that that time is now.
}

Figure captions:

Figure 1: Overview of the structure of the CD-ROM

Figure 2: the structure of Chapter One of the 'Novel as CD-ROM'

Figure 3: A multimodal transcription of the video clip in Chapter One of the 'Novel as CD-ROM'

Figure 4: Three screens from Chapter One of the 'Novel as CD-ROM' 